\title{
Mental Health among Elderly Inmates: Mini Review
}

\author{
Upasen $R^{*}$ \\ Faculty of Nursing, Chulalongkorn University, Thailand
}

*Corresponding author: RatchaneekornUpasen, Faculty of Nursing, Chulalongkorn

University, Borommaratchachonnanisrisataphat Building, the 11th floor, Rama I road,

Bangkok, 10330, Thailand, Tel: +6683-776-2828; Email: Upasen.r@gmail.com

\section{Mini Review}

Volume 3 Issue 2

Received Date: June 08, 2019

Published Date: July 16, 2019

DOI: $10.23880 / \mathrm{mhrij}-16000130$
Elderly inmates are considered as a vulnerability group of prisoners. There are amount of elderly inmates increasingly in many countries as Thailand. The elderly inmates who are 60 years or older are arrested because they need to offense about substance; be guardian and offender instead of their descendants; living lonely; need to be cared by staff of the Prions or Detention centers; and need to have food in each day, peers, and caregivers during staying in the Prison or Detention center. However, when the elderly inmates live in the Prison or Detention centers, they are facing with mental health problems and other negative impacts $[1,2]$. Some of the elderly inmates are suffering with chronic illness as physical and intellectual disability $[3,4]$. They are also considered as a group prison that has special needs because of vulnerability persons $[1,5,6]$. As a result, they gain mental health problems. If they cannot decrease or cope with the mental health problems, they may gain mental disorder or mental illness, such as depression and suicidal idea or suicidal attempt [4].

\section{Mental Health Problems in Elderly Inmates}

Mental health is defined as a state of well-being in which every individual realizes his or her own potential, can cope with the normal stresses of life, good interpersonal relationship, can work productively and fruitfully, and is able to make a contribution to her or his community $[7,8]$. Internationally, not so many studies have done on mental health among the elderly inmates. However, in Thailand the literature that mentions the mental health of the elderly inmates reports that most of the elderly inmates have faced with frustration, stress, hopelessness, loss of self-roles and respect, and low selfesteem [1]. This is similar to the literature review from other countries presenting the mental health of the elderly prisoners dealing with stress, drugs, and alcohol $[3,9,10]$.

Other studies have found that some inmates are at risk of committing suicide from the long duration of life imprisonment, addictive disorder, psychopharmacological treatment, single cell accommodation, marital status, ethnicity, detention for violent crime; and substance abuse $[9,10]$. The literature also reflects mental health problems and negative consequences or negative impacts of the inmates that should raise concern and promote in more positive ways.

Mental health factors that occur among inmates have not widely been addressed. However, there has been reported that mental health factors affecting older prisoners include the lengthy period of imprisonment, restricted rules and regulations, social support from families, and physical illness. Older inmates are also suffering from chronic illness including heart disease, arthritis, hypertension, and diabetes [1,11]. Frequently seeing fellow inmates' death is one of the factors that cause mental health problems [1].

Thus, it is an important issue to understand related or predicting factors of the mental health among the vulnerable people such as the elderly inmates. The elderly inmates have needs and concerns that are distinct from other younger inmates [12]. The elderly inmates' mental health should not be overlooked. This literature review reflects the understanding of influencing factors affecting the elderly inmates' mental health and being considered very important. The health professionals should understand these influential factors of mental health problems among elderly inmates in order to effectively plan for helping the elderly inmates. 


\section{Mental Health \& Human Resilience International Journal}

\section{References}

1. Piyaporn Tunneekul (2018) Concept of welfare management for elderly inmates.

2. Department of Correction, Ministry of Justice (2017) Process to assist prisoners in prisons and detention centers.

3. Gallagher EM (2001) Elderly in prison: health and well-being of older inmates. International Journal of Law and Psychiatry 24(2-3): 325-333.

4. Barry MM, Jenkins R (2007) Implementing mental health promotion. Churchill Livingstone Elsevier, Toronto.

5. Handtke V, Bretschneider $\mathrm{W}$, Elger $\mathrm{B}$, Wangmo $\mathrm{T}$ (2015) Easily forgotten: Elderly female prisoners. Journal of Aging Studies 32: 1-11.

6. Heidari R, Wangmo T, Galli S, Shaw DM, Elger BS, et al. (2017) Accessibility of prison health care for elderly inmates, a qualitative assessment. Journal of forensic and legal medicine 52: 223-228.
7. WHO (2018) Mental health: a state of well-being. World Health Organization.

8. WHO (2001) World Health Report 2001, Mental health: new understand new hope. World Health Organization, Geneva.

9. Rabe K (2012) Prison structure, inmate mortality and suicide risk in Europe. International Journal of Law and Psychiatry 35(3): 222-230.

10. Fazel S, Cartwright J, Norman-Nott A, Hawton K (2008) Suicide in Prison: A systematic review of risk factors. The Journal of Clinical Psychiatry 69(11): 1721-1731.

11. Department of Correction, Ministry of Justice (2012) Growing old in Prison.

12. Kapoor R, Dike C, Burns C, Carvalho V, Griffith EE (2013) Cultural competence in correctional mental health. International journal of law and psychiatry 36(3-4): 273-280. 